www.jmscr.igmpublication.org

Index Copernicus Value: 79.54

ISSN (e)-2347-176x ISSN (p) 2455-0450

crossrefDOI: https://dx.doi.org/10.18535/jmscr/v7i2.38

\title{
Prevalence of Intestinal Tuberculosis in Cases of Sub-Acute Intestinal Obstruction
}

\author{
Authors \\ Dr Bablu Kumar Saha ${ }^{*}$, Dr Md Mahfuzul Haque ${ }^{2}$, Dr Bhupal Chandra Barman ${ }^{3}$, \\ Dr Md Tofael Hossain Bhuiyan ${ }^{4}$ \\ ${ }^{1}$ Associate Professor, Paediatric Surgery Department, Rangpur Medical College, Rangpur, Bangladesh \\ ${ }^{2}$ Assistant Professor, Paediatric Surgery Department, Rangpur Medical College, Rangpur, Bangladesh \\ ${ }^{3}$ Assistant Registrar, Paediatric Surgery Department, Rangpur Medical College, Rangpur, Bangladesh \\ ${ }^{4}$ Professor, Department of Neurosurgery, Rangpur Medical College, Rangpur, Bangladesh
}

*Corresponding Author

Dr Bablu Kumar Saha

Email:drsahaps@gmail.com

\section{Abstract}

Background: Sub-acute intestinal obstruction resulting from intestinal tuberculosis is more prevalent in developing countries including Bangladesh.

Objective: To evaluate the prevalence of intestinal tuberculosis in sub-acute intestinal obstruction in relation to age, sex, social class, occupation and residence.

Methods: This Prospective observational cross sectional study was done at Rangpur Medical College Hospital, Rangpur from December 2013 to June 2014 where 50 patients were selected by purposive sampling as a diagnosed case of sub acute intestinal obstruction. During the study in formed written consent was taken from each of the patients or legal guardians before taking any interview. The consent form clearly describes the purpose and method of the study. After enrollment of the relevant data from history, physical examination and investigations, the information was recorded in predesigned case record form.

Results: The data analysis of 50 patients yielded the following results. Among the 50 patients with sub-acute intestinal obstruction, 20 (40\%) patients were from 31-40 years age group followed by 41-50 years age group where the numbers of respondents were 15(30\%). Male to female ratio was 4:1. 72\% respondents were rural people.

Conclusion: Prevalence of sub-acute intestinal obstruction due to intestinal TB is increasing in TB-endemic countries such as south-east Asia. Due to the lack of characteristic specific symptoms and signs and the fact that laboratory findings are commonly non-specific or show no abnormality, diagnosis of such cases is difficult. Further studies are needed for better outcome.

Keywords: Sub-acute intestinal obstruction, intestinal tuberculosis, immunization.

\section{Introduction}

Tuberculosis has been declared a global emergency by the World Health Organization (WHO) in 1995 and it is the most important communicable disease worldwide. Approximately one third of the world population is infected and about three millions die each year from this disease. It remains the principal cause of death in 
the developing countries $^{123}$, probably due to poverty, lack of education, low detection rate, non-availability of experienced staff and insufficient coverage of the community by immunization programme. The incidence of tuberculosis also rises in developed countries, due to the migration of people from third world countries, HIV infection and increasing use of Immuno-suppressive therapy. However, Multidrug-resistant tuberculosis (MDR-TB) arises from a mixture of physician error and patient noncompliance during treatment of susceptible TB. There should be a strong suspicion of MDR-TB, in persons with a history of prior treatment or in treatment failure cases. The disease may involve any system of the body but abdomen is one of the commonest site of involvement after lungs.

The organism responsible for causing tuberculosis in different organs was first described by German biologist "Robert Koch". The Koch's bacillus' was later on called as Tubercle bacillus'. There are two species of mycobacterium which cause Tuberculosis in human being, the mycobacterium tuberculosis hominis and mycobacterium tuberculosis bovis.

These bacteria cause disease mainly in immune compromised individuals. The primary intestinal tuberculosis is due to ingestion of contaminated food with tubercle bacilli. It may be infected milk of animal or food contaminated with saliva of infected person.

The disease is secondary when the swallowing of infected sputum from an active cavitating primary focus in the lungs causes it. The mesenteric lymph nodes and peritoneum are involved secondarily in the bacteriemic phase that can occur during active primary pulmonary tuberculosis.

The mycobacteria cause chronic disease with a characteristic granulomatous lesion containing collection of epithelioid cells and langerhan's giant cells, but caseation occurs only in tuberculosis. There are two common types of abdomimal tuberculosis; intestinal tuberculosis and tuberculous peritonitis. Rarely the third entity, is the tuberculous lymph adenitis. ${ }^{[1][2][3]}$

Worldwide, one person out of three is infected with Mycobacterium tuberculosis, two billion people in total. The disease usually affects the lungs although in up to one third of cases other organs are involved. It can involve any part of the gastrointestinal tract from mouth to anus, the peritoneum and the pancreatobiliary system. It has a wide variety of presentation, frequently mimicking other common and rare diseases. Abdominal tuberculosis is predominantly a disease of the young adult

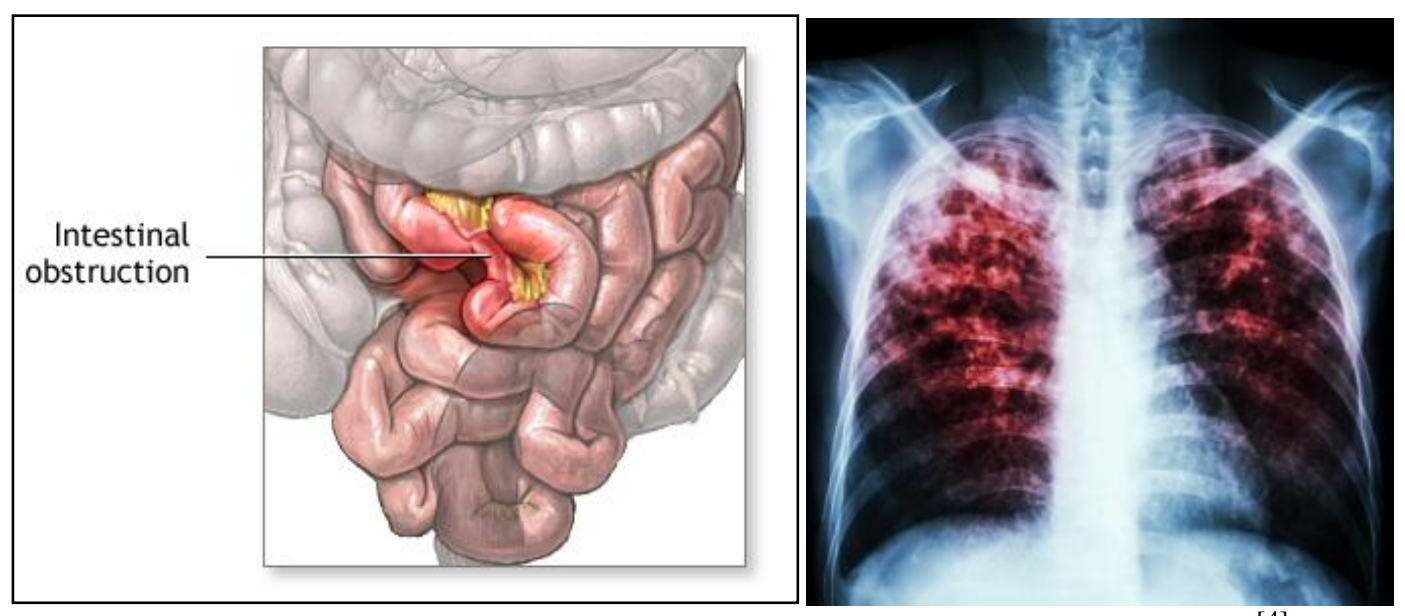

Figure-1a and 1b: Sub-acute intestinal obstruction and tuberculosis ${ }^{[4]}$

The most common site of involvement is the ileocaecal region. The classic histological findingis a caseating granuloma. In this study our main goal is to assess the prevalence of intestinal tuberculosis in sub-acute intestinal obstruction in 
relation to age sex, social class, occupation and residence.

\section{Objective}

\section{General objective}

To evaluate the prevalence of intestinal tuberculosis in sub-acute intestinal obstruction in relation to age sex, social class, occupation and residence.

\section{Specific Objectives}

To study the clinical and pathological characteristics of patients with intestinal tuberculosis and to discuss methods needed to reach the diagnosis.

$>$ To confirm intestinal tuberculosis as a cause of sub-acute intestinal obstruction by histopathological examination.

\section{Methodology}

Study type

$>$ This study was a prospective cross sectional Study.

\section{Study setting and Period}

$>$ This study was done in Rangpur Medical College Hospital from December 2013 to June 2014.

\section{Source of Materials}

Materials of the study were our admitted patient in all five unites of General Surgery as well as Gastroenterology and Pediatric Surgery ward. Those patients who had sub-acute intestinal obstruction were included in this study. A total 50 admitted patients with diagnosed sub-acute intestinal obstruction were selected for the study. This is a prospective study conducted in 7 months period.

\section{Sample size}

$>$ Sample size was selected using the following statistical formula $: \mathrm{n}=Z^{2} p q / \mathrm{d}^{2}$

Here, $\mathrm{n}=$ sample size,

$\mathrm{Z}=1.96$ (at $95 \%$ confidence level)

$\mathrm{p}=$ the proportion of intestinal tuberculosis in cases of sub-acute intestinal

obstruction is $03-25 \%$ in Indian subcontinent. $q=1-p=1.0 .03=0.97$

$\mathrm{d}=$ degree of accuracy desired, usually set at 0.05

Calculation: $\mathrm{n}=Z^{2} p q / \mathrm{d}^{2}$

$\underline{1.96^{2} \times \mathbf{0 . 0 3 \times 0 . 9 7}}$

$0.05^{2}$

$=3.84 \times 0.97 \times 0.03 / 0.0025$

$=44.59$

Therefore the minimum required sample size, $\mathrm{n}=$ 45. But as these patients are available in our country, so we take sample size as 50 .

\section{Purpose and method of the study}

After enrollment of the relevant data from history, physical examination and investigations, the information was recorded in pre-designed case record form. Management modalities include conservative, peri operative and post operative events with complications and follow-up; all were recorded in document sheet specially prepared. Initially most of these patients were relieved by conservative management that is, by keeping them abstained from oral diet, naso-gastric suction and parenteral supplementations. Significant relief was within the period of $6 \mathrm{hr}$ to $48 \mathrm{hr}$. The patient who had acute symptoms of obstruction with no relief in 6 hours were put in the category of acute intestinal obstruction and were not included in the study.

\section{Sampling Techniques}

$>$ Samples were taken from only admitted patients in Surgery department who had subacute intestinal obstruction followed by clinical and laboratory evidence. So, a non probability purposive sampling was done.

\section{Inclusion criteria}

$>$ Patients, who gave written consent, willing to comply with the study procedure are included.

$>$ 2) All admitted patients who were diagnosed as sub-acute intestinal obstruction.

\section{Exclusion criteria}

$>$ Patients with acute intestinal obstruction. Methods: 
After admission data for my study was collected by-

- Direct interview from the patients and their relatives, accompanying persons with detailed history.

- Thorough clinical examination

- Clinical findings and relevant investigations (ultrasonogram. Plain X-ray abdomen) performed over the patient.

After initial resuscitation of the patients, thorough assessment of the patients were done. Documentations of the patients that included identification, history, clinical findings, investigations, operative findings, post operative outcome, complications during the stay in hospital and during subsequent follow up of the patients, all were recorded in a specially prepared proforma, Demographic data were collected including age, sex, occupation, clinical findings, investigation findings, peroperative findings, hospital stay etc.

\section{Statistical data analysis}

$>$ The statistical analysis was performed using statistical package for social science (SPSS) version 12.0 for Windows (SPSS, Chicago IL, U.S.A). The mean + standard deviation (SD), median and ranges were calculated for continuous variables whereas proportions and frequency tables were used to summarize categorical variables. Chi-square (x2) test were used to test for analysis.

\section{Results}

In table- 1 shows Distribution of age $f n=50$ where out of 50 patients maximum patients belong to age group 31-40 years (40\%) followed by age group 41-50 years $(30 \%)$. The minimum number of patients was from 9-20 years age group (6\%). According to mean age, the affected male patients were a little younger than the female patients. The following table is given below in detail:

Table-1: Distribution of age $\mathrm{N}=50$

\begin{tabular}{|c|c|c|c|}
\hline Age group ( years) & No of patient & & Total $(\%)$ \\
\hline $\begin{array}{c}\text { Male } \\
(\mathrm{n}=40)\end{array}$ & & Female $(n=10)$ & \\
\hline $9-20$ & $02(5 \%)$ & $01(10 \%)$ & $03(6 \%)$ \\
\hline $21-30$ & $05(12.5 \%)$ & $01(10 \%)$ & $06(12 \%)$ \\
\hline $31-40$ & $17(42.5 \%)$ & $03(30 \%)$ & $20(40 \%)$ \\
\hline $41-50$ & $12(30 \%)$ & $03(30 \%)$ & $15(30 \%)$ \\
\hline $51-60$ & $01(2.5 \%)$ & $02(20 \%)$ & $03(6 \%)$ \\
\hline$>60$ & $03(7.5 \%)$ & $00(0 \%)$ & $03(6 \%)$ \\
\hline Total & $40(80 \%)$ & $10(20 \%)$ & $50(100 \%)$ \\
\hline Mean age $\pm S D$ & $34.49 \pm 7.54$ & $37.20 \pm 5.89$ & \\
\hline
\end{tabular}


In figure-2 shows gender distribution of the patients where most the patients were male $80 \%$ and female were less $20 \%$. The following figure is given below in detail:

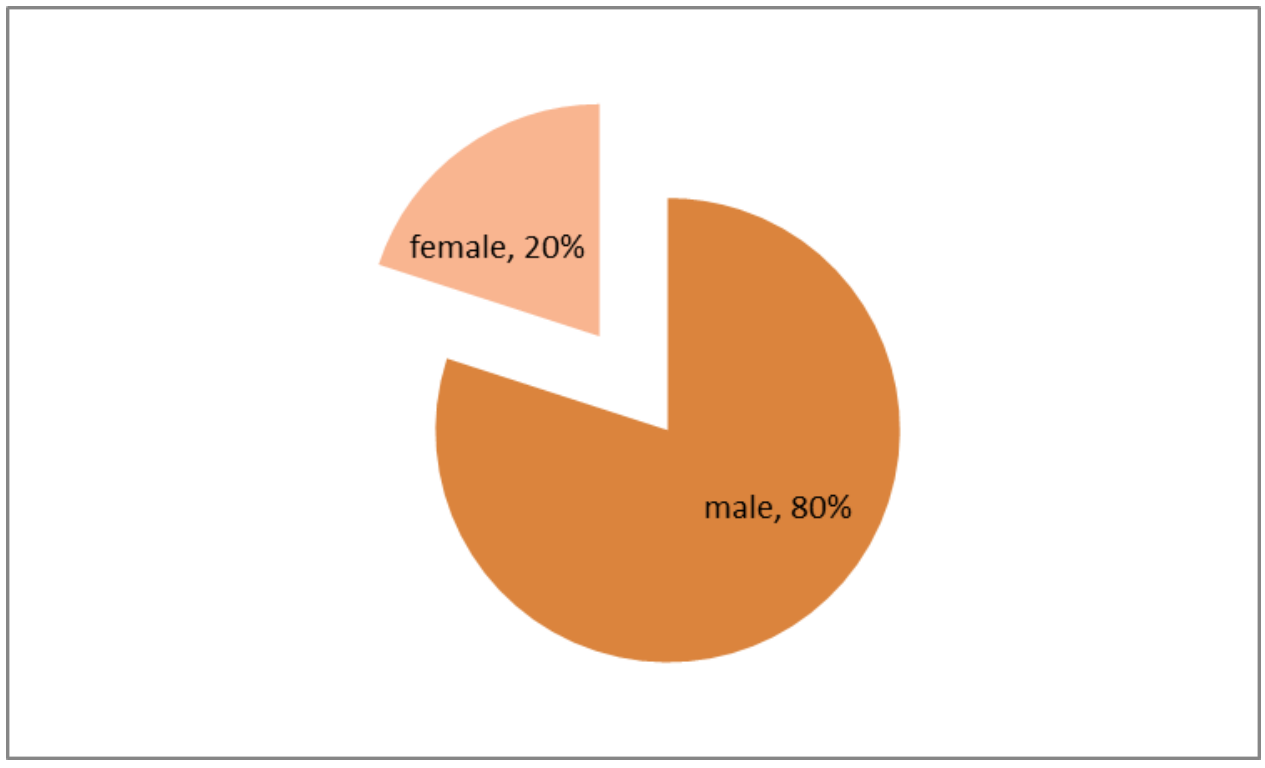

Figure-2: Gender distributions

In figure-3 shows distribution of the patients according to residential area where most of them were inhabitant to rural area $72 \%$ and $28 \%$ inhabitant to urban area. The following figure is given below:

\section{Residence of Patients}

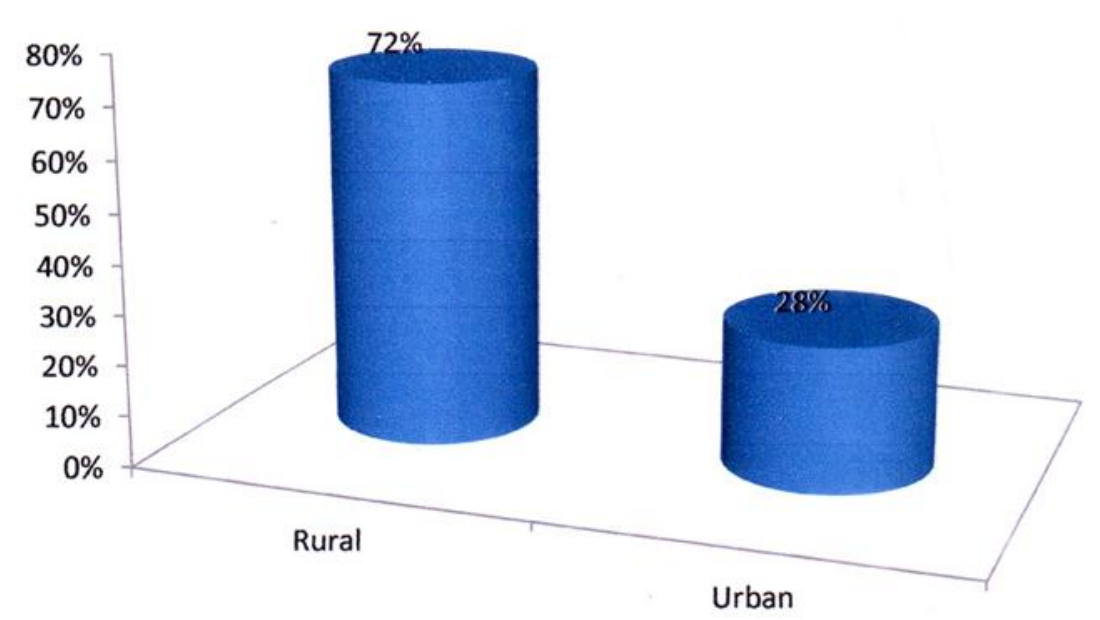

Figure-3: distribution of the patients according to residential area

In figure-4 shows distribution of socioeconomically status where out of 50 patients $76 \%$ were from lower class flowed by $20 \%$ and
$4 \%$ upper class. The following figure is given below in detail: 


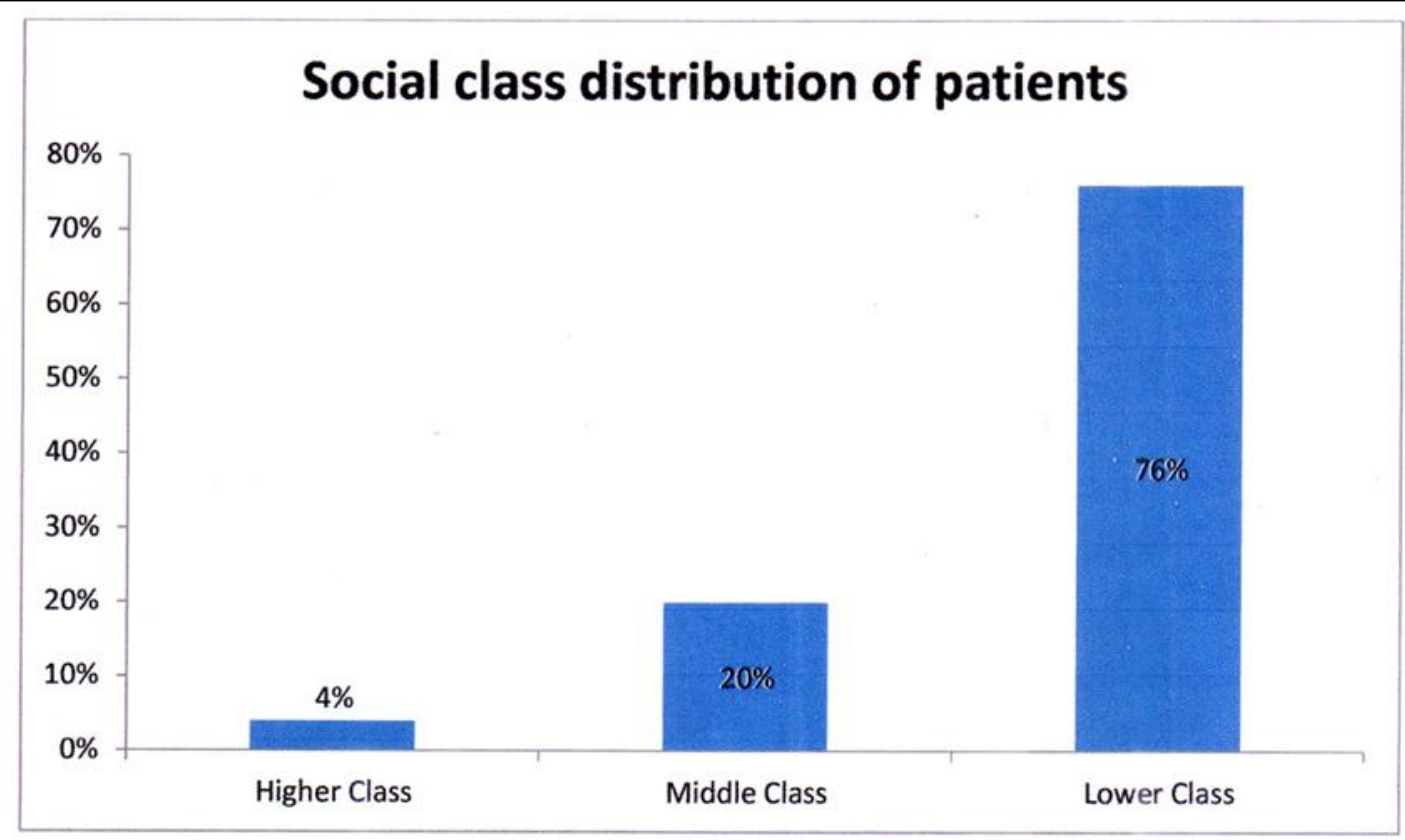

Figure-4: social class distribution of patients.

In figure-5 shows distribution of the patients according to occupation where highest number of the patients were service holder $61.54 \%$. But in this study maximum patients were doing job in
BIRI factories in Rangpur zone. The minimum number of the students was businessman and student. (7.69\%) The following figure is given below in detail:

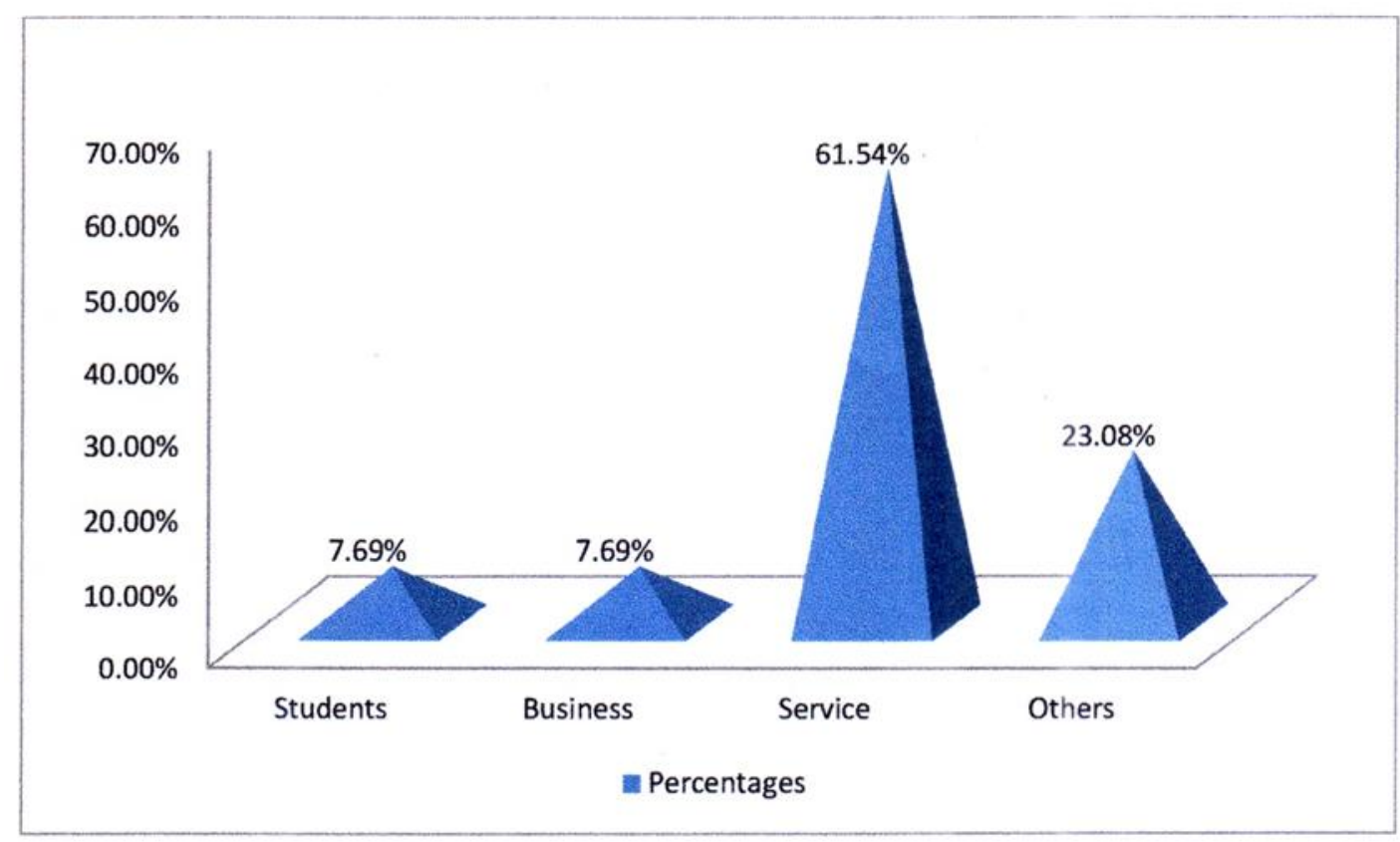

Figure-5: distribution of the patients according to occupation 
In table-2 shows different causes in patients with sub-acute intestinal obstruction $\mathrm{fn}=50$ where Bands and adhesions was common causes in our study population. The following table is given below in detail:

Table-2: Different causes in patients with sub-acute intestinal obstruction $(n=50)$

\begin{tabular}{|lcc|}
\hline Age group (years) & Number of patients & Percentage (\%) \\
\hline intestinal tuberculosis & 13 & 26 \\
\hline Bands and adhesions & 16 & 32 \\
\hline Colonic carcinoma & 11 & 22 \\
\hline Meckel'sdiverticuium & 3 & 6 \\
\hline Crohn's disease & 2 & 4 \\
\hline Incisional hernia & 4 & $\mathbf{8}$ \\
\hline Traumatic diaphragmatic hernia & 1 & 100 \\
\hline Total= & 50 & formula \\
\hline
\end{tabular}

In figure-6 shows Prevalence of intestinal Tuberculosis in our study population $(\mathrm{n}=50)$ where in the 7 months of the study period total 50 patients were admitted with the diagnosis of subacute intestinal obstruction. Among them 13 were finally diagnosed as intestinal tuberculosis.
According to formula of prevalence, the prevalence of ITB among the subacute intestinal obstruction the rate of prevalence as like followsPrevalence rate of $\mathrm{ITB}==26 \%$. Among 13 patients $46.54 \%$ reveled associated intestinal Tuberculosis. The figure is given below in detail:

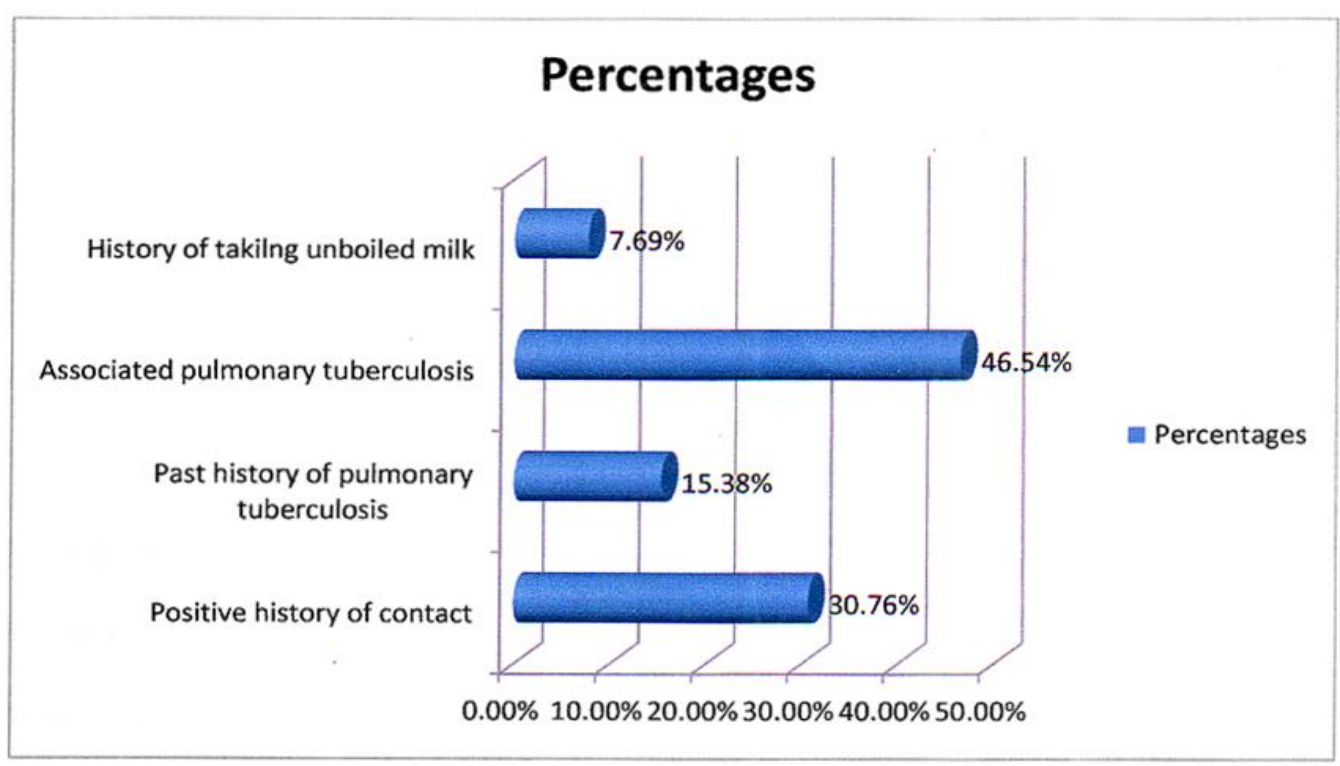

Figure-6: Prevalence of intestinal Tuberculosis

In table-3 shows Clinical Features of Study Population $(n=50)$ where Out of 50 patients all patients were admitted with abdominal pain followed by weight loss $(28 \%)$. The minimum number of people were admitted with cough and sputum $(6 \%)$. The following table is given below in detail:

Table-3: Clinical Features of Study Population $(n=50)$

\begin{tabular}{lcc}
\hline Symptoms \& Signs & Number of patients & Percentage $(\%)$ \\
\hline Abdominal pain & 50 & 100 \\
Weight loss & 28 & 56 \\
Visible peristalsis & 26 & 52 \\
Low grade Fever & 26 & 52 \\
Vomiting and nausea & 22 & 44 \\
Mass in the lower quadrant & 7 & 14 \\
Ascites & 4 & 8 \\
Cough and sputum & 3 & 6 \\
\hline
\end{tabular}


In table-4 shows Investigation findings among the patients with intestinal tuberculosis $(n=13)$ where maximum patients diagnosed as intestinal tuberculosis with sub-acute intestinal obstruction proclaimed anemia $(84.61 \%)$ followed by significant findings in plain x-ray abdomen and histopathology $(76.92 \%)$.

Table-4: Investigation findings among the patients with intestinal tuberculosis $(n=13)$

\begin{tabular}{|c|c|c|}
\hline Laboratory findings & Jumber of patients & Percentage $(\%)$ \\
\hline \multicolumn{3}{|l|}{ Laboratory parameter: } \\
\hline Anaemia & 11 & 84.61 \\
\hline Elevated ESR & 09 & 69.23 \\
\hline \multicolumn{3}{|l|}{ Imaging: } \\
\hline \multicolumn{3}{|l|}{$\mathrm{X}$-ray abdomen in erect } \\
\hline posture (dilated loops with air fluid & 10 & 76.92 \\
\hline \multicolumn{3}{|l|}{ level) } \\
\hline Barium meal and follow through & 08 & 61.54 \\
\hline \multicolumn{3}{|l|}{ (stenotic lesions) } \\
\hline \multicolumn{3}{|l|}{ Ultrasound findings: } \\
\hline Mass in right iliac fossa & 06 & 46.15 \\
\hline Dilated loops and enlarged mesenteric lymph nodes. & 09 & 69.23 \\
\hline Free fluid in peritoneal cavity & 04 & 30.76 \\
\hline \multicolumn{3}{|l|}{ Colonoscopy: } \\
\hline \multicolumn{3}{|l|}{ Showing ulcers, nodules or } \\
\hline strictures. & 09 & 69.23 \\
\hline \multicolumn{3}{|l|}{ Histopathology } \\
\hline Caseating granulomatous lesion. & 13 & 100 \\
\hline
\end{tabular}

In table-5 shows operative findings/Pathological characteristics among the patients with intestinal Tuberculosis $\mathrm{fn}=13$ ) where According to pathological characteristics, small bowel stricture was the commonest manifestation (61.54\%) followed by multiple macroscopic nodules $(53,84 \%)$. The minimum number of patients showed ascitic fluid and multiple adhesions $(28.57 \%)$.The following table is given below in detail:

Table-5: Operative findings / Pathological characteristics among the patients with intestinal Tuberculosis $(n=13)$

\begin{tabular}{|l|c|c|}
\hline Operative findings & Frequency & Percentage (\%) \\
\hline Small bowel strictures (single/multiple) & $\mathbf{0 8}$ & $\mathbf{6 1 . 5 4}$ \\
\hline Multiple macroscopic nodules & $\mathbf{0 7}$ & $\mathbf{5 3 . 8 4}$ \\
\hline lleocaecai mass & $\mathbf{0 5}$ & $\mathbf{3 8 . 4 6}$ \\
\hline Enlarged mesenteric lymph mode & $\mathbf{0 5}$ & $\mathbf{3 8 . 4 6}$ \\
\hline Ascitic fluid & $\mathbf{0 4}$ & $\mathbf{2 8 . 5 7}$ \\
\hline Adhesions & $\mathbf{0 4}$ & $\mathbf{2 8 . 5 7}$ \\
\hline
\end{tabular}

In figure-7, shows duration of hospital stay of the patients where maximum patients stay 11-20 days

$(60 \%)$. The following figure is given below in detail:

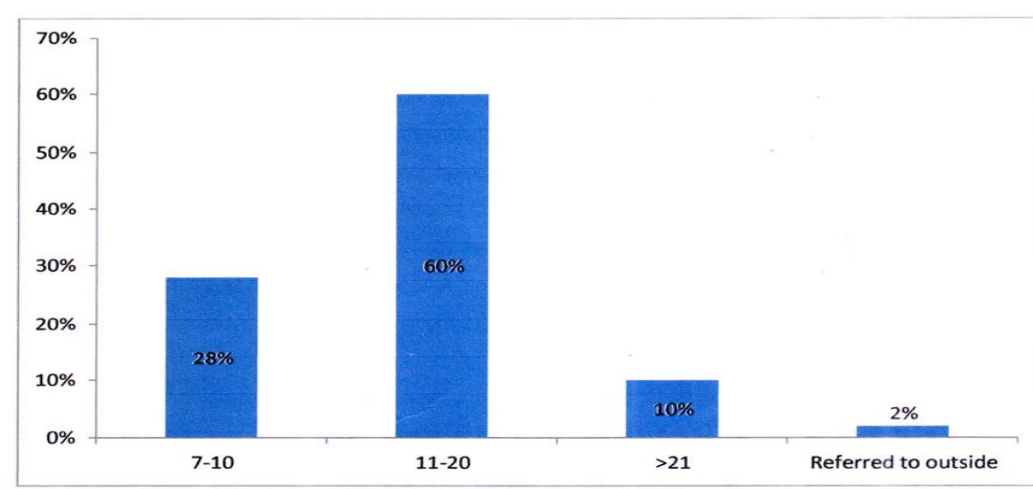

Figure-7: Duration of hospital stay of the patients 


\section{Discussion}

Intestinal tuberculosis is not an uncommon clinical problem in developing countries and also reemerging in the developed countries due to its association with acquired immunodeficiency syndrome. More than hundred years have passed since the identification of the organism. Still the disease is a worldwide problem. Intestinal tuberculosis is an important cause of morbidity in the Bangladeshi population, because the diagnosis is delayed. It is rightly termed as a continuing problem.

Tuberculosis has re-emerged as a devastating disease during the last decade with a high morbidity and mortality. Bangladesh among with other five nations account for more than $50 \%$ of tuberculous cases worldwide. The disease is considered to be the fourth major cause of all deaths in Pakistan and the second commonest cause of intestinal obstruction. ${ }^{[5]}$ TB of the gastrointestinal tract is the sixth most frequent form of extra-pulmonary site ${ }^{[6]}$

It has varied presentation, frequently mimicking other common and rare diseases. This study reports the socio-demographic factors, prevalence and clinical presentation which would help the physician to diagnose and treat this curable disease. From the 50 patients, $40(80 \%)$ were male and $10(20 \%)$ were female. Male and female ratio was 4:1. On e study also showed male predominance in his study. Here most of the patients were in the age of 31-40 years and average age was $34.49 \pm 7.54$ years, which is similar to other study ${ }^{[6][7]}$. A previous study from our country also reported similar type of results. It is also known that two thirds of the patients with intestinal TB are 21-40 years old. In this study we found such an observation. Common presentation were, abdominal pain (100\%), low grade fever $(52 \%)$, weight loss $(56 \%)$, nausea and vomiting (44\%), which were similar to other report. ${ }^{[8]}$ Abdominal lump and abdominal lymphadenopathy were $14 \%$ whereas another study found $16.8 \%$ tuberculosis lymphadenitis ${ }^{[9]}$ and other study showed abdominal mass $13 \% .^{[10]}$
In this series average $\mathrm{Hb} \%$ was $8.5 \mathrm{gm} / \mathrm{dl}$ which were similar to other study. ${ }^{[9][11]}$ Plain X-ray abdomen showed significant abnormalities in $76.92 \%$ cases other study found abnormal findings in the same series of $x$-ray in case of $75 \%$ of the patients. ${ }^{[12]}$ USG revealed abnormality in $69.23 \%$ of cases and predominant findings were dilated loops and enlarged mesenteric lymph nodes.In $46.15 \%$ cases, right iliac fossa mass and in $30.76 \%$ cases free fluid of ascites which is similar to other study ${ }^{[13]}$ Colonoscopy revealednodularity and ulceration in $69.23 \%$, and narrowing in $6 \%$ of cases which is similar to other study. ${ }^{[12]}$ So ulcerative lesion is common in intestinal TB. Ascitic fluid study revealed exudative fluid with lymphocyte predominance but no AFB was found .Histopathology reports were consistent with granulomatous lesion that means tuberculosis in $100 \%$ cases .In this study no patients with intestinal tuberculosis died, out of 13- All presented late with sub-acute intestinal obstruction, 46.54\% had associated pulmonary tuberculosis. Different studies quote a mortality rate associated with gut perforation ranging from $11 \%$ to $45 \%^{[14]}$ The management of abdominal TB requires conventional anti TB for at least 6 months including initial 2 months of rifampicin, INH, Pyrazinamide and Ethambutol. in our study though all the patients were treated with 6 month regime.

\section{Limitation}

> This is single blinded, single centered study.

$>$ Duration is short.

$>$ Sample size is small.

$>$ Does not proclaim the scenario of whole country

\section{Recommendations}

$>$ A multicentered double blinded study in the divisional/ tertiary hospitals of whole Bangladesh can reveal the real picture of intestinal tuberculosis in case of subacute intestinal obstruction.

$>$ The study period should be long. 
$>$ Multi disciplinary approach of research work can make a study precise \& more authentic in this regard.

The whole country patient's conditions should be recorded so that we can generate a protocol as a national guideline for effective management of intestinal tuberculosis.

\section{Conclusion}

Intestinal tuberculosis is one of the major causes of morbidity and mortality in the developing countries. It mostly presents as acute abdomen in the form of sub-acute intestinal obstruction with the signs and symptoms of intestinal obstruction or perforation. The patients usually admitted in surgery with sub-acuteintestinal obstruction aremostly from low socioeconomic status with low education profile. Male are mostly affected due to more exposure in outdoor work.

A high index of suspicion, proper evaluation, and therapeutic trial in suspected patients is essential for an early diagnosis and timely treatment, in order to decrease the prevalence of complications. The core message in this study is that diagnosing intestinal TB entails a clinical challenge and should hinge on bearing a great awareness of the disease by physicians.

\section{Reference}

1. World Health Organization Bulletin in Epidemiology of Tuberculosis, 2002.

2. Suri S, Gupta S. CT scan in Abdominal Tuberculosis, Br J Radio! 1999; 72: 92-98.

3. Sharp JF, Goldman M. Abdominal Tuberculosis in East Brimingham, a 16 years study. Postgrad Med J 2002; 63: 539-42.

4. https://www.google.com/search?q=tubercul osis\&client $=$ firefox $-b-$

ab\&source $=\operatorname{lnms} \&$ tbm $=i$ sch $\& s a=X \&$ ved $=0$ ahUKEwjkuY7o0LDfAhXKYo8KHQihA0 4Q_AUIDigB\&biw=1366\&bih=618\#imgrc =vZTQxBLjesgEeM:
5. Baluch N, Tafaii M, Durrani K, Ahmad M. Abdominal tuberculosis. A varied presentation. Pak. J. Med. Res 1993; 32(4): 259-262.

6. Iliyasu Z, Babashani M. Prevalence and predictors of tuberculouscoinfection among HIVseropositive patients attending the Aminu Kano Teaching Hospital, northern Nigeria. J Epidemiol 2009; 19:81-87.

7. MP Sharma, Bhatia V. Abdominal tuberculosis. Indian J. Med. 2004; 120(4): 305-15.

8. Kishore PV, ChandrsekharTS, Paiaian S. Diagnosing Abdominal Tuberculosis: A Retrospective Study From Nepal. The Internet Journal of Gastroenteroiogy 2008; 6(2): 87-89.

9. Uzunkoy A, Harma M, Harrna M, Diagnosis of abdominal tuberculosis: experience from 11 cases and review of the literature, World J Gastroenterol. 2005; 11 (21): 3328.

10. Muneef M A, Memish Z, Mahmoud SA, Sadoon SA, Bannatyne R, Khan Y. Tuberculosis in the belly: a review of forty-six cases involving the gastrointestinal tract and peritoneum. Scand J Gastroenterol 2001;36(5): 528-32.

11. Mukerjee P, RajorR.Abdominal Tuberculosis. Ind. J. Tub; 26 (2): 62-66.

12. Sinkala E, Gray S, Zulu I et al. Clinical and uitrasonographic features of abdominal tuberculosis in HIV positive adults in Zambia. BMC Infect Dis 2009; 9:44.

13. Bayramicli 0, Dabak G, Dabak R. A clinical dilemma: abdominal tuberculosis. World $\mathrm{J}$ Gastroenterol 2003; 9(5): 1098-101.

14. Sircar S, Taneja VA, Kausra V. Epidemiology and clinical presentation of Abdominal Tuberculosis, a retrospective study. J Indian Med Assoc 1996; 94(9): 342-4. 